\title{
ANÁLISE DO USO E COBERTURA DA TERRA EM ÁREA DE PRESERVAÇÃO PERMANENTE NA SUB-BACIA DO CÓRREGO CAMPESTRE, MUNICÍPIO DE CAMPESTRE/MG
}

\author{
Gabriele Caroline dos Reis Lago ${ }^{1}$ \\ Paulo Henrique de Souza ${ }^{2}$ \\ Rodrigo José Pisani ${ }^{3}$
}

RESUMO: Este estudo desenvolveu uma análise do uso e cobertura da terra e dos conflitos identificados nas áreas de preservação permanente na sub-bacia do Córrego Campestre, no município de Campestre/MG, através do emprego da metodologia de geoindicadores. Para tanto utilizou softwares de Sistema de Informação Geográfica como o ArcMap 10.5.1 para a manipulação dos dados obtidos a partir das imagens de satélite do CBERS - 4A, disponibilizadas no portal do Instituto Nacional de Pesquisas Espaciais (INPE). Também fez uso das técnicas do sensoriamento remoto e do processamento digital de imagens para se obter a quantificação dos mapas elaborados; sendo eles: Mapa de Localização do Município; Mapa de Solos do Município; Mapa de Uso e Cobertura da Terra; Mapa de Conflitos de Uso e Ocupação das Áreas de Preservação Permanente do Córrego Campestre; Mapa do Modelo Digital de Elevação da Sub-Bacia do Córrego Campestre e Mapa de Uso e Ocupação na Sub-Bacia do Córrego Campestre. Através do inventário feito, constatou-se a presença de diversos conflitos nas áreas de preservação permanente, causados principalmente pela ausência de planejamento urbano, desmatamento da mata nativa, descarte irregular de lixos, lançamento de esgoto nos cursos d'água dentre outros.

PALAVRAS-CHAVE: Expansão Urbana; Geoindicadores; Impactos Ambientais; Geotecnologias; Drenagem.

\section{ANALYSIS OF LAND USE AND COVERAGE IN A PERMANENT PRESERVATION AREA IN THE CÓRREGO CAMPESTRE WATERSHED, MUNICIPALITY OF CAMPESTRE/MG}

\footnotetext{
${ }^{1}$ Licenciada em Geografia pela UNIFAL-MG; gabriele.lago@sou.unifal-mg.edu.br

2 Professor Associado do ICN e do PPGEO da UNIFAL-MG; paulohenrique.souza@unifalmg.edu.br

3 Professor Adjunto do ICN e do PPGEO da UNIFAL-MG e orientador do projeto; rodrigo.pisani@unifal-mg.edu.br
} 
ABSTRACT: This study developed an analysis of the use and coverage of land and the conflicts identified in the areas of permanent preservation in the sub-basin of Córrego Campestre, in the municipality of Campestre/MG, through the use of geoindicators methodology. To do so, it used Geographic Information System software such as AcrMap 10.5.1 to manipulate the data obtained from CBERS - 4A satellite images, available on the National Institute for Space Research (INPE) portal. It also made use of remote sensing and digital image processing techniques to obtain the quantification of the elaborated maps; namely: Location Map of the Municipality; Soil Map of the Municipality; Land Use and Coverage Map; Map of Conflicts of Use and Occupation of Permanent Preservation Areas of Córrego Campestre; Digital Elevation Model Map of the Córrego Campestre Sub-Basin and Use and Occupation Map of the Córrego Campestre SubBasin. Through the inventory made, the presence of several conflicts in permanent preservation areas was found, mainly caused by the absence of urban planning, deforestation of native forest, irregular garbage disposal, sewage discharge into waterways, among others.

KEYWORDS: Urban Expansion; Geoindicators; Environmental impacts; Geotechnologies; Drainage.

\section{ANÁLISIS DE USO Y COBERTURA DEL TERRENO EN UNA ZONA DE CONSERVACIÓN PERMANENTE DE LA SUB-CUENCA CÓRREGO CAMPESTRE, MUNICIPIO DE CAMPESTRE/MG}

RESUMEN: Este estudio desarrolló un análisis del uso y cobertura del suelo y los conflictos identificados en las áreas de preservación permanente en la subcuenca de Córrego Campestre, en el municipio de Campestre / MG, mediante el uso de la metodología de geoindicadores. Para ello, utilizó el software del Sistema de Información Geográfica como AcrMap 10.5.1 para manipular los datos obtenidos de las imágenes del satélite CBERS - 4A, disponibles en el portal del Instituto Nacional de Investigaciones Espaciales (INPE). También utilizó técnicas de teledetección y procesamiento de imágenes digitales para obtener la cuantificación de los mapas elaborados; a saber: Mapa de ubicación del municipio; Mapa de suelos del municipio; Mapa de uso y cobertura del suelo; Mapa de Conflictos de Uso y Ocupación de Áreas de Conservación Permanente de Córrego Campestre; Mapa del Modelo Digital de Elevación de la Subcuenca del Córrego Campestre y Mapa de Uso y Ocupación de la Subcuenca del Córrego Campestre. A través del inventario realizado, se encontró la presencia de varios conflictos en áreas de preservación permanente, causados principalmente por la ausencia de planificación urbana, deforestación de bosque nativo, disposición irregular de basura, vertido de aguas residuales a cursos de agua, entre otros.

PALABRAS CLAVE: Expansión Urbana; Geoindicadores; Impactos ambientales; 
Geotecnologías; Drenaje.

\section{INTRODUÇÃO}

Em face da gravidade e repercussão dos impactos causados sobre o meio ambiente, bem como pela crescente conscientização da população, leis têm sido aprovadas para auxiliarem na resolução desse problema como a Resolução $n^{\circ}$ 001/86 do Conselho Nacional do Meio Ambiente - CONAMA que conceitua impacto ambiental e se une ao artigo 225 da Constituição Federal (BRASIL, 1988).

Todavia, por mais que tal arcabouço legal esteja sendo incrementado, um longo caminho precisa ser percorrido na harmonização da relação do homem com a natureza, sobretudo nos ambientes situados nos domínios da urbanidade que altera significativamente o sítio que ocupa, transformando permanentemente a paisagem e interferindo em suas adjacências.

Sob esse entendimento a realização de um estudo de caso que promova o inventário e análise das áreas de preservação permanente coaduna-se com essa busca, pois, permite a identificação dos impactos que se encontram estabelecidos; cuidando em identificar suas origens e as ações que devem ser implementadas para seu equacionamento, servindo de base e orientação para outras ações de natureza semelhante noutras porções do espaço terrestre, utilizando em seu desenvolvimento dois os parâmetros e apoios fornecidos pelos geoindicadores e geotecnologias.

Sobretudo quando os avanços científicos e tecnológicos fornecem uma base ampla, sólida e consistente para o desenvolvimento das pesquisas que se ocupam das ações humanas no espaço e suas consequências para o meio ambiente e sociedade, pois de um lado os geoindicadores auxiliam com conceitos, dados e parâmetros, enquanto que as geotecnologias fornecem os instrumentais e recursos para a análise das informações espaciais.

Segundo Berger e lams (1996, p. 5) 
Os geoindicadores são medidas (magnitudes, frequências, taxas e tendências) de processos geológicos e fenômenos que ocorrem na/ou próximo da superfície terrestre e estão sujeitos a mudanças, que são significativas para o entendimento das alterações ambientais num período de cem anos ou menos. São mudanças não-biológicas em ambientes geológicos, que podem causar perturbações irreversíveis ao ecossistema numa escala ou outra. Estão incluídas tantas alterações rápidas (eventos catastróficos) como processos mais lentos, que são geralmente evidentes na escala de vida humana.

Por seu turno, Rosa (2005) define geotecnologias como o conjunto de tecnologias para coleta, processamento, análise e oferta de informações com referência geográfica, sendo compostas por soluções em hardware, software e peopleware que juntos constituem poderosa ferramenta para análise e tomada de decisões.

No bojo das geotecnologias encontram-se relacionadas a cartografia digital (CD), sensoriamento remoto (SR), sistemas de informação geográfica (SIG), sistema de posicionamento global (GPS) e a topografia.

Uma vez que a Constituição Federativa do Brasil (BRASIL, 1988) em seu Capitulo VI - Do Meio Ambiente estabelece através do seu artigo 225 a responsabilidade do Poder Público pela manutenção do meio ambiente em benefício de cada cidadão nesta e nas futuras gerações; cumpre aos entes federativos a busca por estratégias que assegurem o cumprimento desta determinação legal, assim como a aplicação de outras leis ocupadas com o disciplinamento da relação do homem com o meio ambiente como é o caso da Lei 12.650/2012 (BRASIL, 2012) que estabelece normas gerais para a preservação das Áreas de Preservação Permanente - APP.

Atentando para isto e para a carência de pesquisas desta natureza no município Campestre/MG, a pesquisa foi desenvolvida utilizando os parâmetros fornecidos pelos geoindicadores em associação aos recursos disponibilizados pelas geotecnologias, explorando os mapas de uso e cobertura da terra ao passo 
LAGO, G. C. R; SOUZA, P. H; PISANI, R. J. $\quad$ Análise do uso e cobertura da terra em área de... que identifica e localiza os impactos ambientais nas áreas de preservação permanente em córregos rurais, periurbanos e urbanos no município.

\section{ÁREA DE ESTUDO}

Segundo o Instituto Brasileiro de Geografia e Estatística (2021), o Município de Campestre está localizado no sul de Minas Gerais, na microrregião de Poços de Caldas. Contendo uma população estimada de 21.054 pessoas, uma área total de $577,843 \mathrm{~km}^{2}$ e PIB per capita de $\mathrm{R} \$ 16.350,87$.

Limita-se com os municípios de Botelhos, Caldas, Divisa Nova, Bandeira do Sul, Santa Rita de Caldas, Ipuiuna, Poço Fundo, Machado, Serrania e Poços de Caldas (Figura 1). Conforme a classificação climática de Köppen-Geiger, o clima do município se caracteriza como tropical de altitude. O município apresenta uma altitude máxima de 1.478 metros, na Serra do Tripuí. A menor cota altimétrica, por sua vez, é registrada na foz do Rio do Peixe, com 954 metros e a sede municipal, situada a 1.075,97 metros de altitude. A temperatura média anual está em torno de $18,2^{\circ} \mathrm{C}$, oscilando com média máxima anual próxima de $24,3^{\circ} \mathrm{C}$ e média mínima de $12,9^{\circ} \mathrm{C}$. Apresenta um índice pluviométrico de aproximadamente $1.605 \mathrm{~mm}$. (CAMPESTRE, 2006).

Figura 1: Mapa de Localização do Município de Campestre/MG e Área de Estudo 


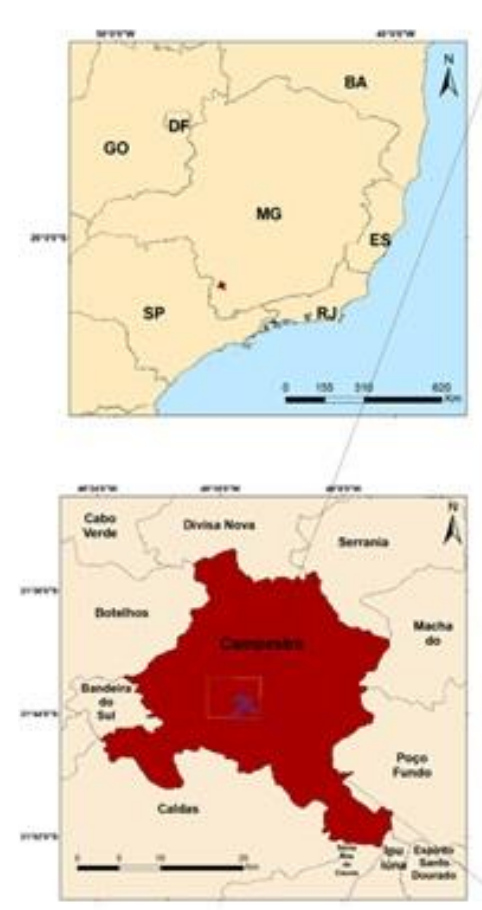

Legenda

Umite Drenagem Drenagem Periurbana
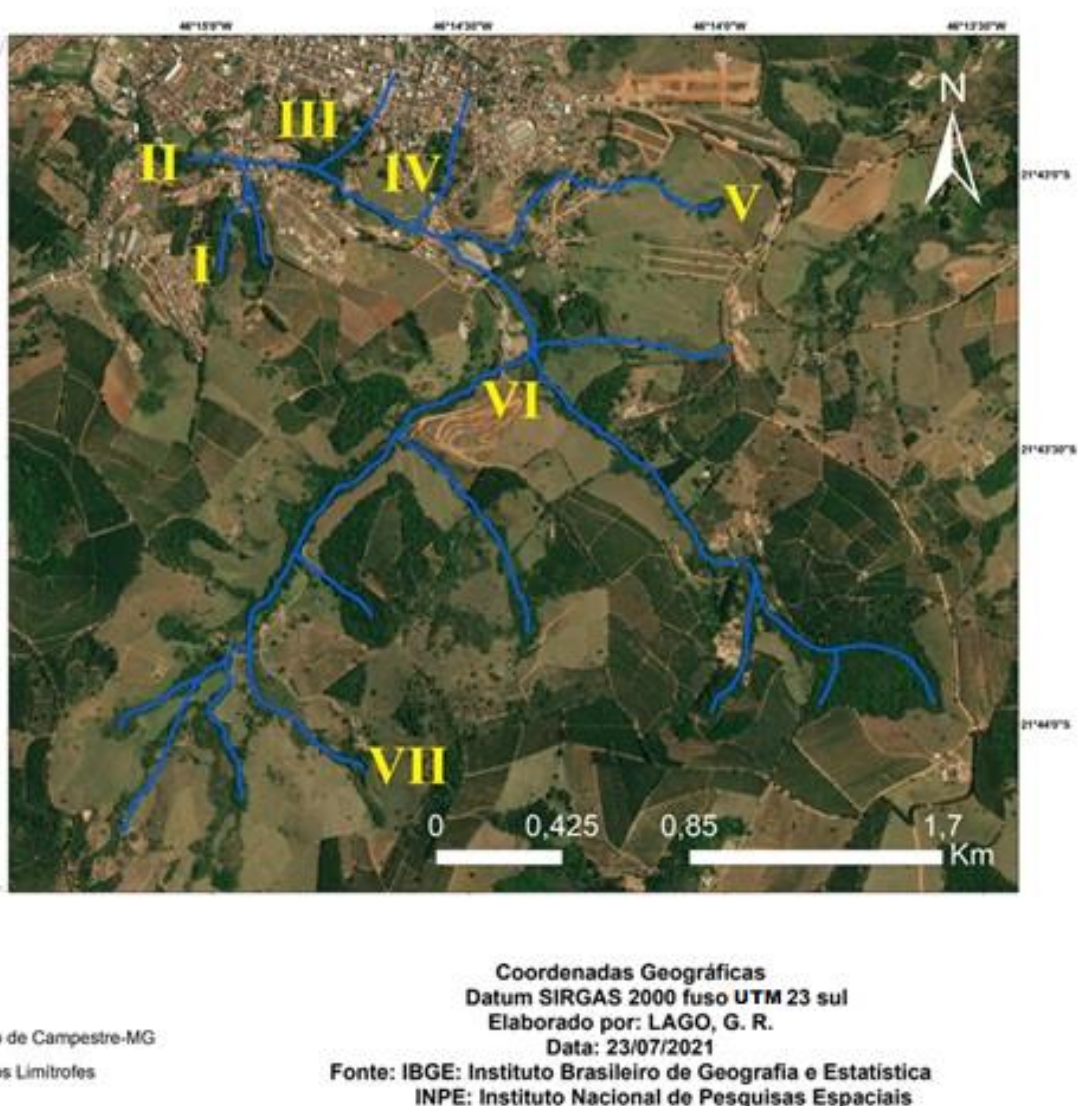

Coordenadas Geográficas

CIRm SIRGAS 2000 fuso UTM 23 sul Data: 23/07/2021

INPE: Instituto Nacional do Pesquisas Espaciais

Fonte: Autores (2021)

A hidrografia do município é composta pelos rios Cabo Verde, Muzambo, Machado, Rio do Peixe e Rio Pardo; fazendo parte da bacia Rio Grande. O relevo é formado por morros de vertentes poli-convexas, com declividades superiores a $30 \%$, abrigando drenagem fluvial retangular estabelecida pelos lineamentos estruturais do Pré-Cambriano. Geologicamente prevalecem rochas do précambriano granito-gnáissicas. A estrutura geológica deu origem aos diferentes tipos de solos, como: Latossolo Vermelho-Amarelo, Latossolo Vermelho-Escuro, Argissolo Vermelho-Escuro, Argissolo Vermelho-Amarelo e Cambissolo. (CAMPESTRE, 2006).

\section{MATERIAIS E MÉTODOS}

Para a realização do presente trabalho foi utilizada a ferramenta Google Earth Pro para a realização da análise prévia e escolha da área de estudo. A 
LAGO, G. C. R; SOUZA, P. H; PISANI, R. J. Análise do uso e cobertura da terra em área de... partir disto definiu-se os materiais e métodos, assim como a área de estudo. Após isto teve lugar a revisão bibliográfica. O levantamento de dados com as buscas cartográficas, análise de imagens de satélite e trabalho de campo.

A elaboração do mapa de uso e cobertura da Terra utilizou 3 imagens orbitais do satélite CBERS 4A, sensor WPM, com resolução espacial de 8 metros, data: 11/06/2021, com ocorrência mínima de cobertura de nuvens do município de Campestre/MG, obtidas por meio do cadastro de imagens gratuitas do Instituto Nacional de Pesquisas Espaciais-INPE (INPE, 2021b); sendo elas:
1) Cena 1: órbita 203 ponto 140
2) Cena 2: orbita 202 ponto 141
3) Cena 3: orbita 202 ponto 140

A montagem da drenagem da área de estudo foi feita pelo download dos arquivos (tipo DGN) das redes de drenagem e das cartas topográficas de 1:50.000, no portal do IBGE (2021), de Campestre/MG, Botelhos/MG, Caldas/ MG e Rio Capivari/MG.

Todas as etapas de construção do mapa como o pré-processamento, que corresponde a análise e interpretação de imagens, o processamento e o pósprocessamento, relacionado a quantificação dos dados e elaboração dos mapas finais, foram realizadas pela ferramenta ArcMap 10.5.1.

No Pré-Processamento de Imagens foi necessário descompactar as imagens obtidas do CEBERS 4A e importá-las para o ArcMap, convertendo da projeção para a UTM fuso 23 Sul e também para o Datum SIRGAS 2000. Também foi feito o recorte da área de estudo para a realização dos testes da composição das bandas; para assim identificar qual seria a melhor composição para distinguir as feições do terreno.

Para a composição de bandas foram utilizados alguns testes com a banda 123 (banda do visível) juntamente com o Basemap; mas ao final definiu-se a banda 234 (RGB - Infra-Vermelho-próximo, Vermelho e Verde) para a melhor interpretação das imagens. 
A partir das composições das bandas teve lugar o Processamento das Imagens, sendo realizada a classificação supervisionada das imagens com o auxílio da coleta de amostras de classes de uso e cobertura da terra, sendo consideradas as seguintes classes:
1) Corpo Hídrico
2) Mata Nativa
3) Solo Exposto
4) Pastagem

Figura 2: Fluxograma da Metodologia Utilizada

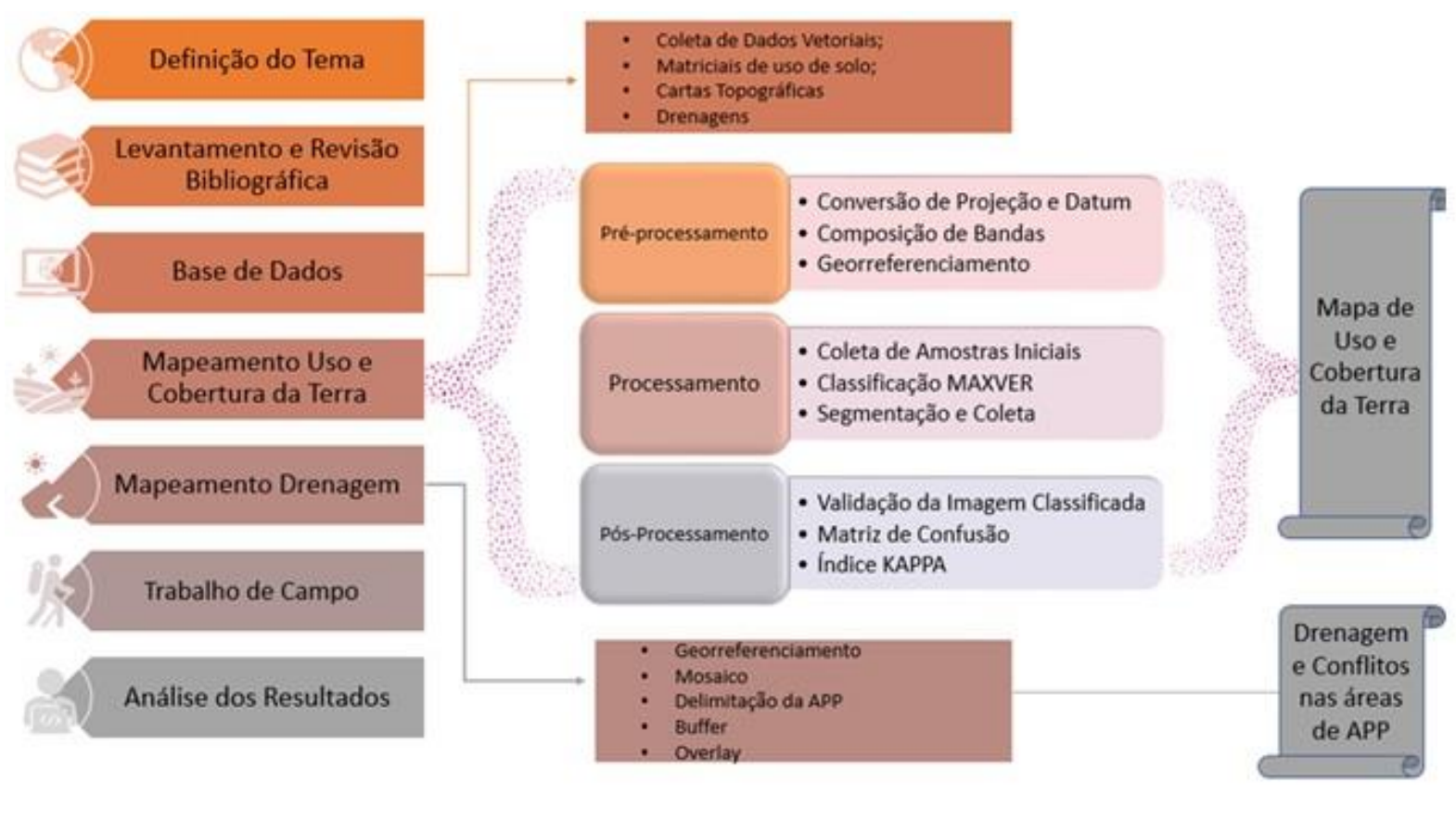

Fonte: Autores (2021)

Após a amostragem foi realizada a classificação supervisionada, pelo método da Máxima Verossimilhança; função que possui o objetivo de classificar o uso e cobertura da terra com as amostras iniciais propostas, verificando suas semelhanças.

Após a geração da imagem classificada, foram identificados os pontos da classificação que deveriam ser ajustados através da segmentação manual de polígono (shape) para melhoria da classificação e posterior extração das classes de interesse, por meio da coleta de amostras desses polígonos, resultando em 
LAGO, G. C. R; SOUZA, P. H; PISANI, R. J. $\quad$ Análise do uso e cobertura da terra em área de... um total de 7 classes de uso e cobertura da Terra, sendo eles:
1) Corpo Hídrico
2) Mata Nativa
3) Solo Exposto
4) Pastagem
5) Área Urbana
6) Culturas Agrícolas
7) Silvicultura.

Finalizando as feições a partir da segmentação, foi feita a transformação do polígono para raster (formato matricial imagem). Esse processo é realizado através da ferramenta mosaico, onde foi efetuada a união da imagem reclassificada com as novas classes de Área Urbana, Culturas Agrícolas e Silvicultura.

No Pós-Processamento das Imagens fez-se necessário testar a acurácia das informações geradas através do índice de Kappa, que é considerado um método estatístico que procura avaliar o nível de concordância entre dois conjuntos de dados (LANDIS; KOCH, 2007).

Para a realização do teste de acurácia foram distribuídos 100 pontos de maneira aleatória através da função Accuracy no ArcMap, a seguir foi gerada a matriz de confusão (Confusion), alcançando o valor de 0,77 para o índice Kappa, possuindo então concordância substancial.

Tabela 1: Classificação do Índice de Kappa

\begin{tabular}{|c|c|}
\hline Índice Kappa & Concordância \\
\hline$<0$ & Inexistente \\
\hline $0-0,20$ & Mínima \\
\hline $0,21-0,40$ & Razoável \\
\hline $0,41-0,60$ & Moderada \\
\hline $0,61-0,80$ & Substancial \\
\hline $0,81-1$ & Excelente \\
\hline
\end{tabular}

Fonte: Adaptação de Landis e Koch (1977)

Para a elaboração do mapa e análises da drenagem foi necessário fazer o 
LAGO, G. C. R; SOUZA, P. H; PISANI, R. J. $\quad$ Análise do uso e cobertura da terra em área de... download de outros arquivos de drenagem com escala de 1:50.000, provenientes das seguintes cartas topográficas:
SF-23-V-D-IV-1 (Botelhos);
SF-V-D-IV-2 (Campestre);
SF-23-V-D-IV-3 (Caldas);
SF-23-V-D-IV-4 (Rio Capivari).

Após o processo de georreferenciamento das cartas foi realizado o procedimento de Union (união) e o recorte do município já com a rede de drenagem (Clip). Em seguida foi aplicado o Buffer sobre as drenagens e depois foi aplicada a função Overlay (máscara - Imagem classificada com o uso e cobertura da terra) pela parte do polígono da área de Área de Preservação Permanente.

\section{RESULTADOS E DISCUSSÕES}

A partir das análises realizadas, foram obtidos os valores para cada classe de uso e cobertura da terra em $\mathrm{Km}^{2}$ e $\mathrm{Ha}$ (hectares) na Área de Preservação Permanente - APP situada na área elegida para estudo para identificação dos impactos ambientais (Tabela 2 e Figura 3).

Tabela 2: Uso e Cobertura da terra na Área de Estudo

\begin{tabular}{|c|c|c|c|}
\hline $\begin{array}{c}\text { Classes de Uso e } \\
\text { Cobertura }\end{array}$ & $\begin{array}{c}\text { Área da APP } \\
\mathrm{Km}^{2}\end{array}$ & Área APP Ha & $\begin{array}{c}\text { Porcentagem em } \\
\text { relação à Área Total }\end{array}$ \\
\hline Corpo Hídrico & 0,001472 & 0,1472 & $0,19 \%$ \\
\hline Mata Nativa & 0,280832 & 28,0832 & $35,45 \%$ \\
\hline Solo Exposto & 0,045056 & 4,5056 & $5,69 \%$ \\
\hline Pastagem & 0,383744 & 38,3744 & $48,44 \%$ \\
\hline Área Urbana & 0,045184 & 4,5184 & $5,70 \%$ \\
\hline Culturas Agrícolas & 0,035840 & 3,584001 & $4,52 \%$ \\
\hline TOTAL & 0,792128 & 79,212801 & $100 \%$ \\
\hline
\end{tabular}


LAGO, G. C. R; SOUZA, P. H; PISANI, R. J. $\quad$ Análise do uso e cobertura da terra em área de...

Após as ações de georreferenciamento, manipulação de dados e análises, a condição de uso e ocupação do solo e consequente localização dos impactos ambientais foi desenvolvida na sub-bacia do Córrego Campestre conforme expressam a Figura 4 e Tabela 3.

Tabela 3: Uso e Ocupação na Sub-Bacia do Córrego Campestre

\begin{tabular}{|c|c|c|c|}
\hline $\begin{array}{c}\text { Classes de Uso e } \\
\text { Cobertura }\end{array}$ & $\begin{array}{c}\text { Sub-Bacia } \\
\text { em Km² }\end{array}$ & $\begin{array}{c}\text { Sub-Bacia } \\
\text { em Ha }\end{array}$ & $\begin{array}{c}\text { \% em relação a } \\
\text { Área Total }\end{array}$ \\
\hline Corpo Hídrico & 0,002432 & 0,2432 & $0,04 \%$ \\
\hline Mata Nativa & 1,44346 & 144,346 & $23,95 \%$ \\
\hline Solo Exposto & 0,304256 & 30,4256 & $5,05 \%$ \\
\hline Pastagem & 2,90592 & 290,592 & $48,21 \%$ \\
\hline Área Urbana & 0,347264 & 34,7264 & $5,76 \%$ \\
\hline Culturas Agrícolas & 1,02368 & 102,368 & $16,98 \%$ \\
\hline TOTAL & 6,027012 & 602,701198 & $100 \%$ \\
\hline
\end{tabular}

Figura 3: Mapa de Uso e Cobertura da terra e Impactos Ambientais 

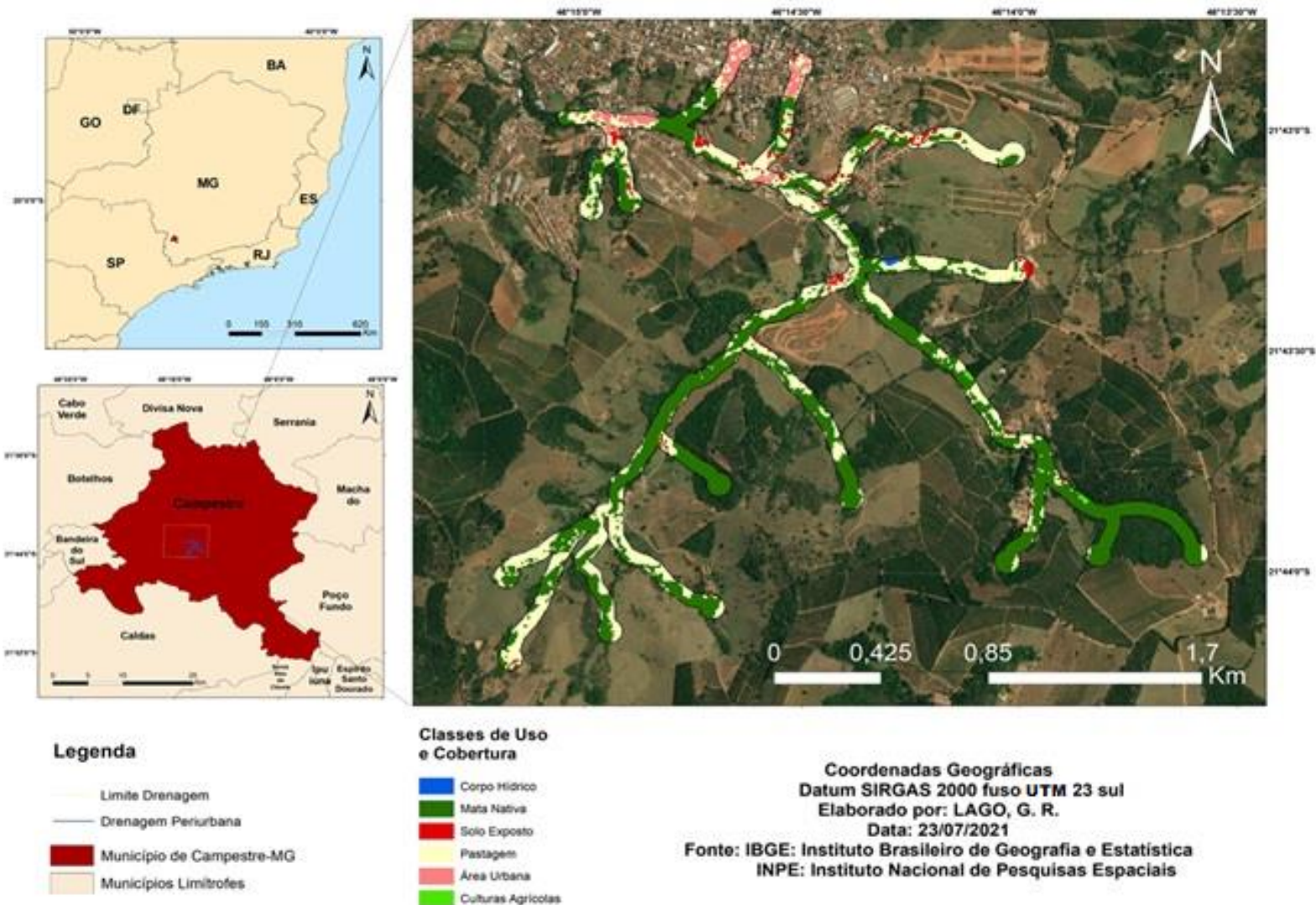

Figura 4: Mapa de Uso e Ocupação na Sub-Bacia do Córrego Campestre

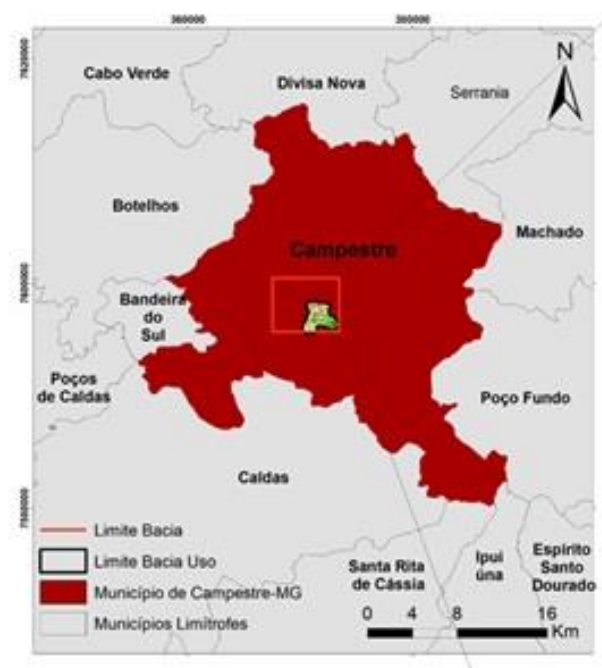

SRC: Universal Transvera de Mercator - UTM Datum: SIRGAS 2000 fuso UTM 23 Sul

Elaborado por: LAGOS, G. R.

Data: 29/07/2021

Fonte

IBGE: Instituto Brasileiro de Geografia e Estatistica INPE: Instituto Nacional de Pesquisas Espaciais

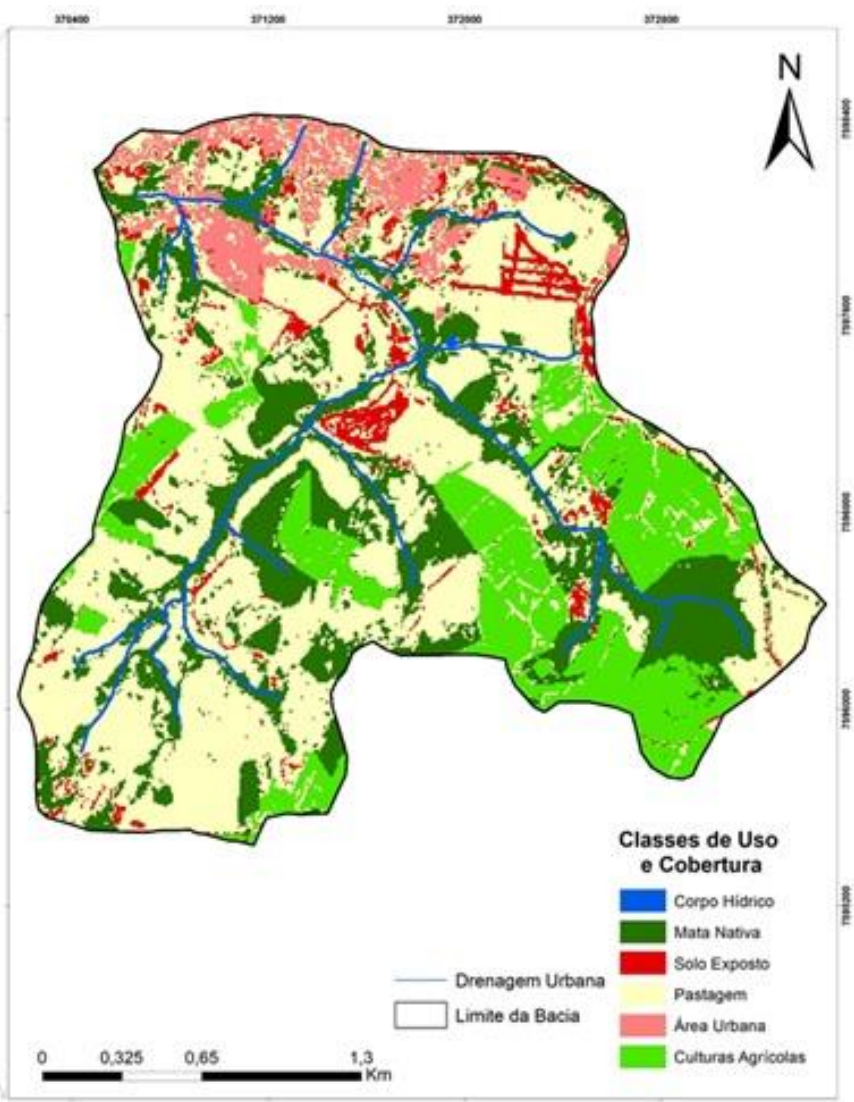

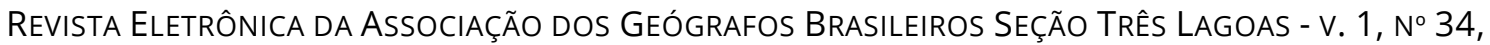


Após a elaboração dos mapas e determinações do Código Florestal Brasileiro que estabelece preservação dos cursos d'água de em $30 \mathrm{~m}$ nas margens e raio de $50 \mathrm{~m}$ nas nascentes, seguiu-se o diagnóstico identificando os impactos ambientais nas Áreas de Preservação Permanente.

\section{IMPACTOS AMBIENTAIS NA ÁREA DE ESTUDO}

O Ponto I (Figura 5) localiza-se próximo à rua Idair Alves de Almeida, bairro: Coabi 1; no local é possível notar a ação antrópica na área de preservação permanente (nascente), reduzindo a mata ciliar, com presença de restos de lixos e vestígios de fogueiras nas proximidades. O Ponto II também é caracterizado pela ação antrópica, uma vez que o curso d'agua é suprimido pelo crescimento da área urbana. Este fica localizado na rua José Borges Franco, bairro: centro (Figura 6).

Figura 5: Nascente do Ponto 1

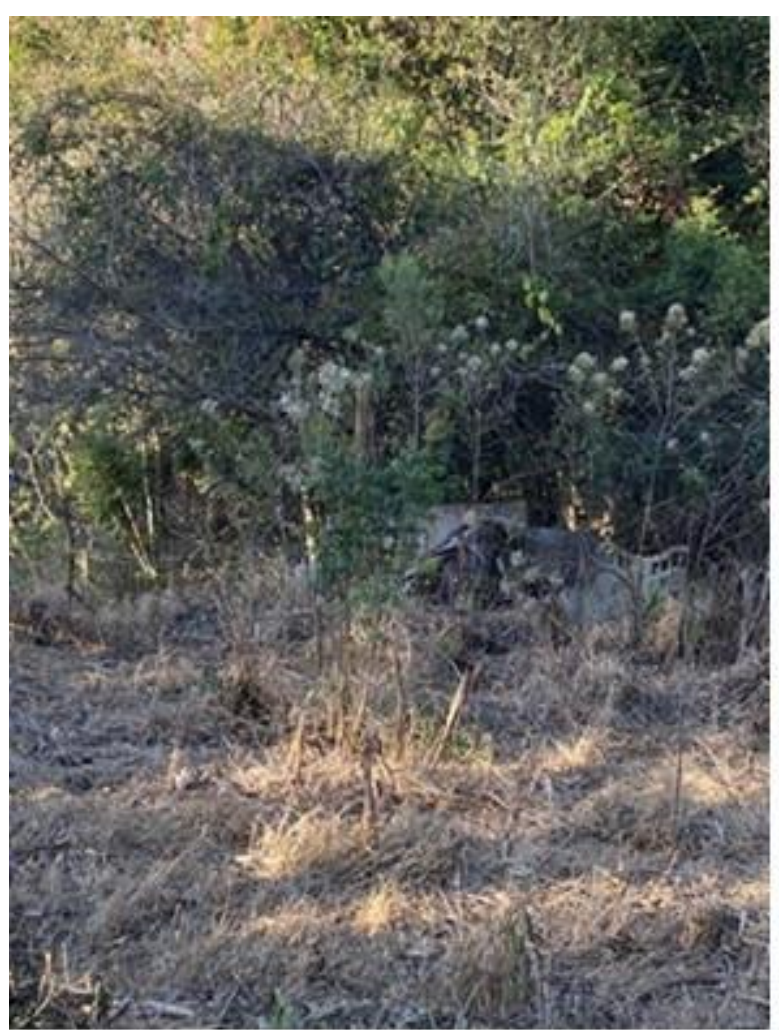

Figura 6: Nascente do Ponto 2

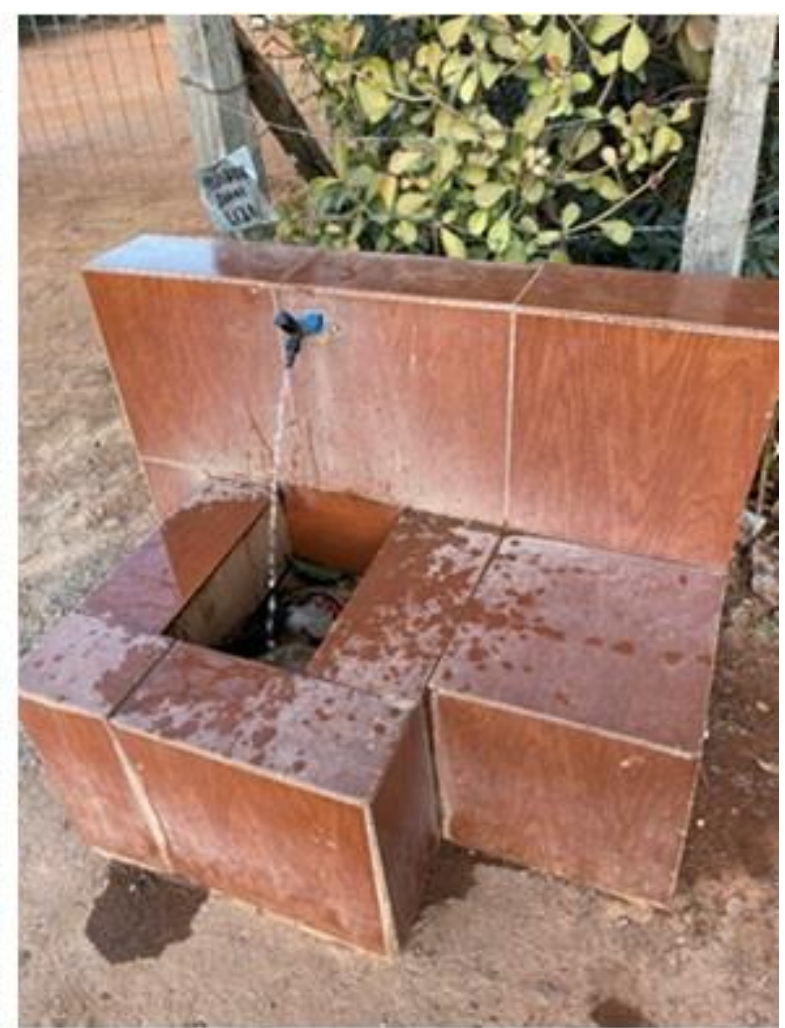


O Ponto III é a paisagem urbana que engoliu uma nascente e curso d'água na rua Doutor Lafaiete Dias de Araujo no centro (Figura 7). O Ponto IV está na rua Chafariz no centro, é uma nascente que fica rodeada pela paisagem urbana em propriedade (terreno) não ocupada (Figuras 8 e 9).

O Ponto $V$ está localizado em uma área periurbana do município. Através do trabalho de campo foi possível constatar a falta de mata ciliar ao longo do curso d'água, assim como de toda a área, tendo apenas resquícios de mata nativa ao redor da nascente (Figura 10). O Ponto VI é também está impactado pela ação antrópica (Figura 11). Com a realização do trabalho de campo foi possível constatar que a compactação provocada pelo trânsito de veículos caracteriza o descaso com a nascente e curso d'água.

Figura 7: Nascente do Ponto 3

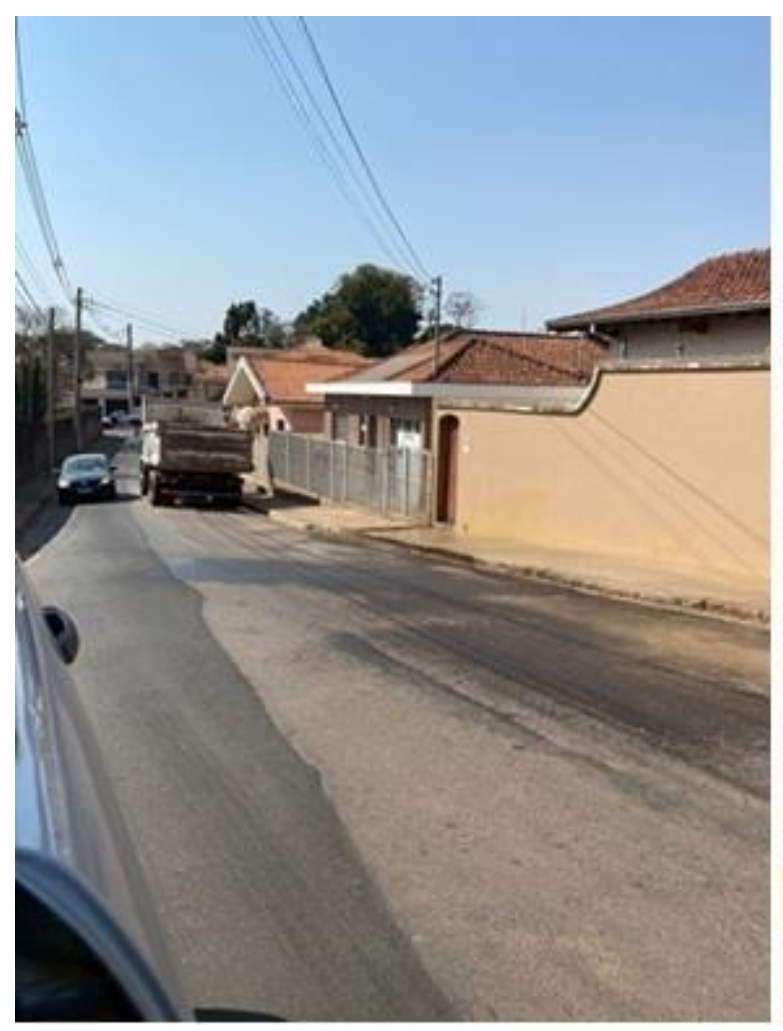

Figura 8: Nascente do Ponto 4

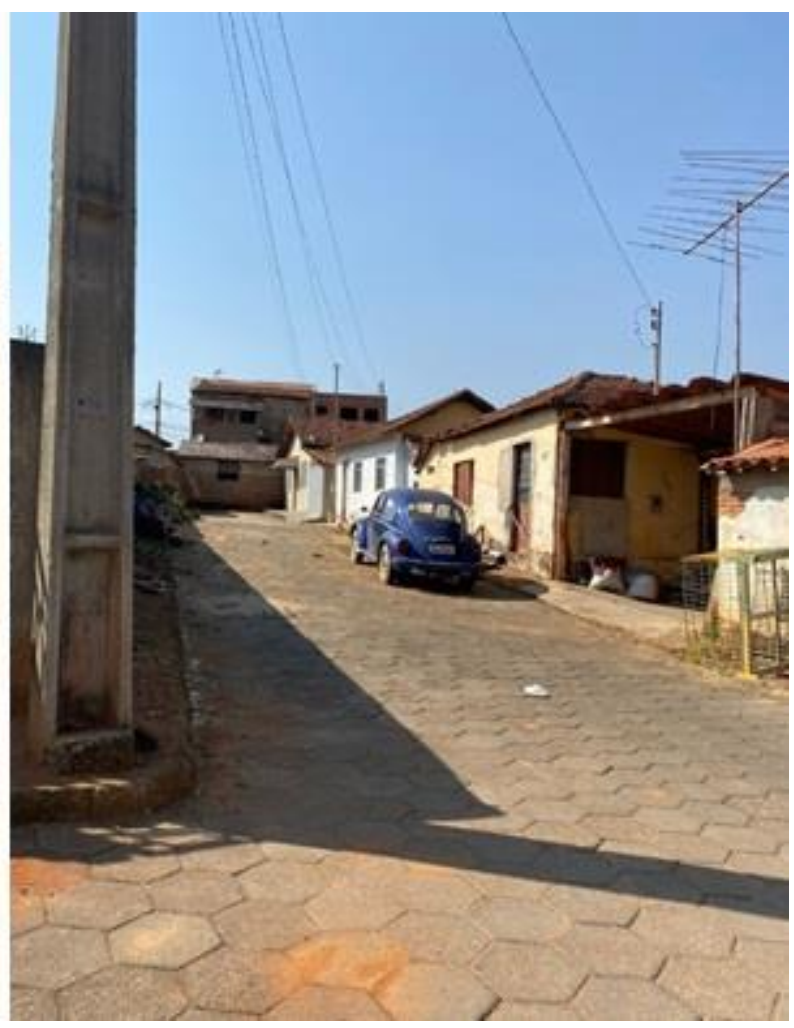

O Ponto VII fica localizado na área rural do município. Nesse caso a antropização da paisagem também interfere através das pastagens que 
substituem a vegetação nativa ainda que seja o ponto que apresenta o menor grau de comprometimento (Figura 12).

Desta forma, conforme é possível observar nos exemplos apresentados, a ação antrópica na incorporação de áreas para o exercício de suas atividades produtivas não tem respeitado os limites ecológicos que salvaguardariam diversos atributos da degradação ambiental.

Figura 9: Nascente do Ponto 4

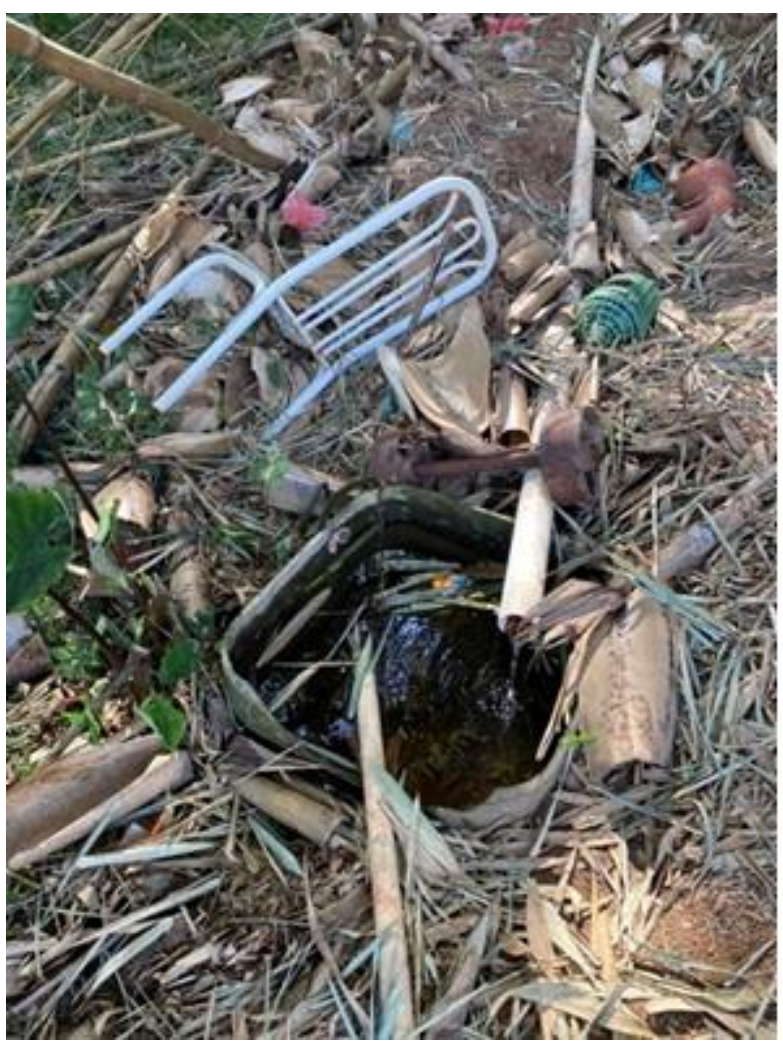

Figura 11: Nascente do Ponto 6
Figura 10: Nascente do Ponto 5

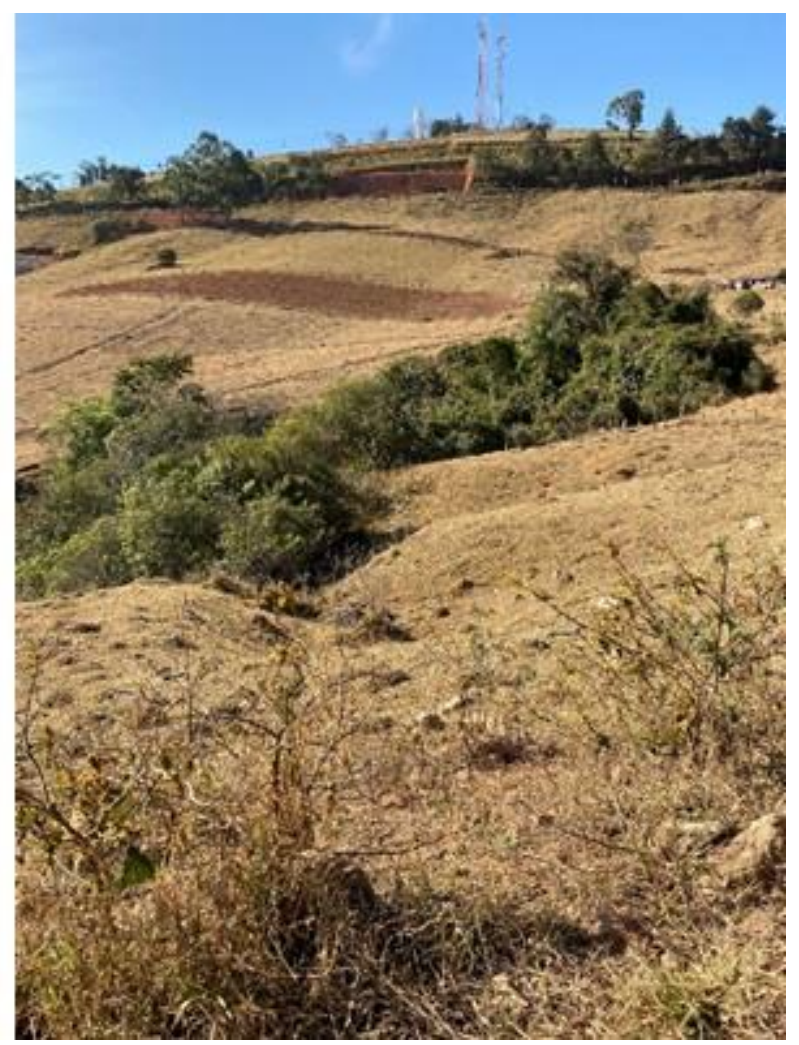

Figura 12: Nascente do Ponto 7 

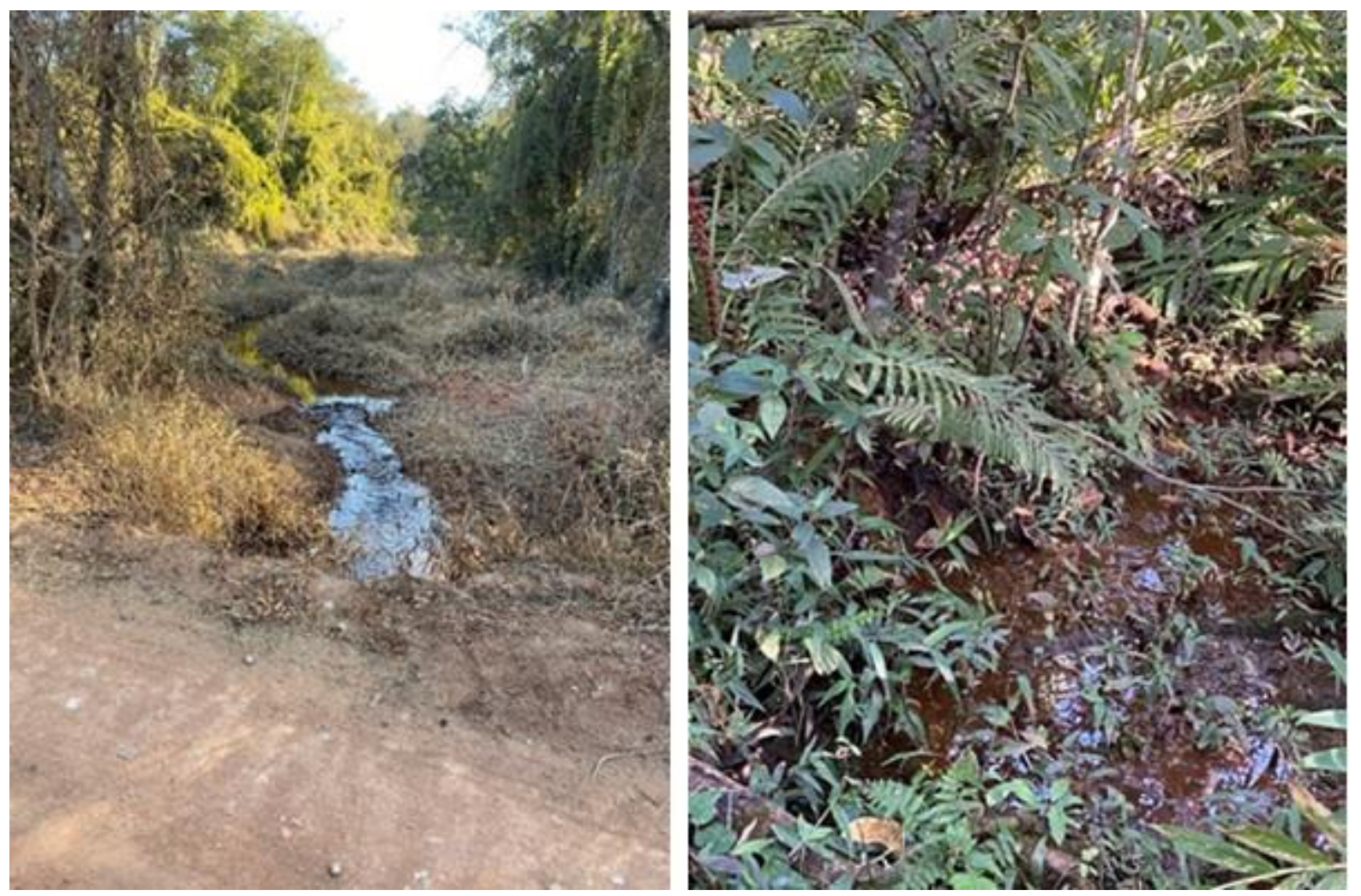

No encerramento desta discussão, apresenta-se através da Figura 13 o mapa de Uso e Cobertura da Terra do município de Campestre/MG para destacar o grau de interferência que a área de estudo já sofreu, enfatizando com isto a urgente revisão que a sociedade local precisa efetuar em suas prioridades e atitudes, tendo em conta os impactos que prosseguem ocasionando no território que ocupam, avançando até mesmo sobre as áreas de preservação permanente.

Tal reflexão é mais que necessária tendo em conta o espaço ínfimo que a vegetação nativa ocupa e o avanço da antropização da paisagem que se verifica às margens dos cursos d'água por toda a área, denunciando o descaso que tem prevalecido na preservação do meio ambiente.

Certamente a governança e a estrutura do Estado também possuem sua cota de responsabilidade por não oferecerem resistência alguma às ações deletérias que ocorreram e ocorrem conforme as Figuras anteriores denunciam. 
Figura 13: Mapa de Uso e Cobertura da Terra do município de Campestre/MG
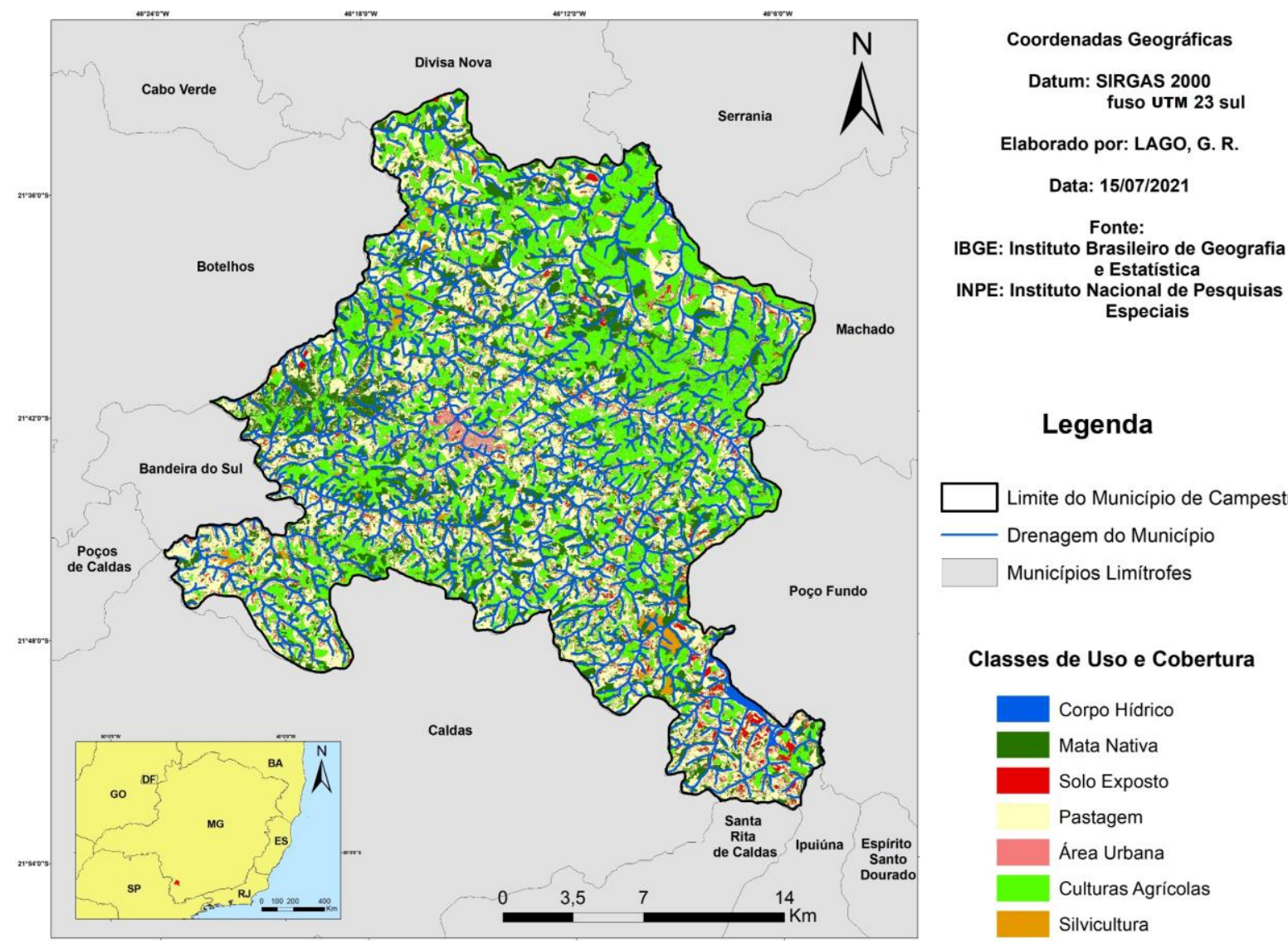

Fonte: Autores (2021)

\section{CONSIDERAÇÕES FINAIS}

É fato notório que a sub-bacia do Córrego Campestre possui vários problemas de uso e ocupação da terra nas diversas porções de seu território, incluído aí suas áreas de preservação permanente, em razão de fatores causados principalmente pelo avanço urbano sobre esses espaços, estimulado pela falta de planejamento, desmatamento da mata nativa, descarte irregular de lixos, lançamento de esgoto nos cursos d'água e supressão do respectivo córrego e seus afluentes.

Entretanto, mesmo sendo de responsabilidade dos órgãos públicos a fiscalização para a conservação das áreas de preservação permanente, fazendo valer a legislação prevista pelo Novo Código Florestal e demais Leis, não se verifica uma atuação efetiva do Poder Público local, favorecendo a conjuntura 
LAGO, G. C. R; SOUZA, P. H; PISANI, R. J. $\quad$ Análise do uso e cobertura da terra em área de... que ocasiona uma série de impactos ambientais que coloca em xeque os atributos naturais para desfrute da presente e futuras gerações.

Obviamente a ação da sociedade civil e dos empreendedores também colabora com essa situação indesejável, pois, os locais identificados no estudo situam-se na área urbana e fora dela, coexistindo com a residência da população e propriedades particulares nas quais os respectivos moradores e detentores dos direitos de posse encontram-se plenamente conscientizado do dano que suas ações causam sobre as áreas de preservação permanente.

No encerramento deste artigo é possível manifestar o atendimento aos objetivos que nortearam o desenvolvimento da pesquisa desenvolvida, principalmente em razão da metodologia utilizada para a análise de uso e ocupação da terra e identificação dos impactos ambientais existentes nas áreas de preservação permanente da área elegida para estudo, utilizando os geoindicadores e as ferramentas de geotecnologias, sendo elas: o geoprocessamento, o sensoriamento remoto e o processamento digital de imagem.

Graças aos esforços despendidos, produtos e resultados significativos foram alcançados, gerando assim mapas com dados qualitativos e técnicos que servirão como aporte para os gestores municipais de Campestre/MG na busca pela mitigação dos impactos ambientais identificados e a correção dos equívocos que cooperaram com o seu estabelecimento.

\section{REFERÊNCIAS BIBLIOGRÁFICAS}

BERGER, A. R.; IAMS, W. T. - Geoindicators - assessing rapid environmental changes in earth systems. Rotterdam: Balkema, 1996. 466p.

BRASIL. - Constituição Federal de 5 de outubro de 1988. Disponível em http://www.planalto.gov.br/ccivil_03/constituicao/constituicao.htm. Acessado em: 08 de setembro de 2021. 
BRASIL. - Lei $n^{\circ}$ 12.650, de 25 de maio de 2012. Disponível em: <http://www.planalto.gov.br/ccivil_03/_ato20112014/2012/lei/l12651compilado.h tm> Acessado em: 07 de setembro de 2021.

CONSELHO NACIONAL DE MEIO AMBIENTE. - Resolução CONAMA n 369, de 28 de março de 2006. Publicada no DOU no 61, de 29 de março de 2006, Seção 1, páginas $150-151$.

INSTITUDO BRASILEIRO DE GEOGRAFIA E ESTATÍSTICA. - Cidades - Campestre. 2021. Disponível

em: <https://cidades.ibge.gov.br/brasil/mg/campestre/panorama> Acessado em: 08 de setembro de 2021.

INSTITUTO NACIONAL DE PESQUISAS ESPACIAIS. - Manuais: Tutorial de Geoprocessamento - Classificação da Imagem. 2021a. Disponível em: <http://www.dpi.inpe.br/spring/portugues/tutorial/classific.html> Acessado em: 08 de setembro de 2021.

INSTITUTO NACIONAL DE PESQUISAS ESPACIAIS. - Teoria: Processamento de Imagens. 2021b. Disponível em: <http://www.dpi.inpe.br/spring/teoria/realce/realce.htm> Acessado em: 05 de setembro de 2021.

LANDIS, J.; KOCH, G. The measurement of observer agreement for categorical data, Washington, USA. Biometrics, v. 33, n. 1, p. 159-174, 1977.

PREFEITURA MUNICIPAL DE CAMPESTRE/MG. - Diagnóstico e Diretrizes para a Estrutura Urbana e do Território Municipal. Vol. I, 2006.

ROSA. R. - Geotecnologias na Geografia Aplicada. Revista do Departamento de Geografia, n 16 (2005) 81-90. 